During the whole trial no significant differences were noted between the diets with respect to feed intake, growth rate and feed conversion ratio. However, the diets containing cereals + the largest amount of shelled horse-beans tended to increase the feed conversion ratio (2.7 p. IOO) and to slow down the growth rate $(2.9 \mathrm{p}$. Ioo). Concerning slaughter performances, the different criteria measured did not show any significant difference between the diets.

When shelled, horse beans can be used at a high level in pig diets without modifying the performances.

However, in order to obtain better feeding costs per pig produced, one must take into account the losses (20 p. roo of the initial product) and expenditures due to the shelling.

\title{
VALEUR ALIMENTAIRE DU « GLUTEN FEED " POUR LE PORC EN CROISSANCE-FINITION
}

\author{
D. BOURDON et Y. HENRY \\ Station de Recherches sur l'Élevage des Porcs, \\ Centre national de Recherches zootechniques, $I . N$. R. A., \\ 78350 Jouy en Josas
}

\section{RÉSUMÉ}

Quatre expériences sont réalisées en vue de préciser la valeur et les possibilités d'utilisation du "Gluten-Feed " comme source azotée complémentaire, dans des régimes à base de maïs, chez le Porc en croissance-finition.

Les résultats des deux premières expériences réalisées sur un total de 164 porcs, permettent de conclure à une utilisation optimale du "Gluten-Feed ", correctement supplémenté en lysine, au taux de 20 p. Ioo. Ainsi, il est possible d'assurer une substitution partielle des protéines de soja complémentaire d'environ 25 p. roo.

De même l'expérience 3 , réalisée en lots sur 96 porcs, démontre clairement qu'un mélange Gluten (40 p. roo de "Gluten-Feed " +60 p. Ioo de gluten de maïs) à 44 p. Ioo de protéines, correctement rééquilibré en lysine et utilisé au taux de 25 p. Ioo, peut assurer 75 p. Ioo de l'apport complémentaire de protéines.

La dernière expérience réalisée en digestibilité sur 16 porcs, a permis une estimation de la valeur énergétique du "Gluten Feed 》 à $2900 \mathrm{kcal}$ d'énergie digestible par kg de matière sèche, correspondant à un CUD apparent de l'énergie de 64 p. Ioo.

\section{SUMMARY}

\section{FEEDING VALUE OF « GLUTEN FEED " FOR GROWING-FINISHING PIGS}

Four experiments were made in order to determine the value and utilization possibilities of "Gluten Feed " as supplementary source of crude protein in diets based on maize given to growingfinishing pigs. 
The first two experiments realized with a total of 164 pigs showed an optimum utilization of "Gluten-feed " correctly supplemented with lysine $(20$ p. Ioo). Thus, a partial substitution of complementary soya-bean proteins (about $25 \mathrm{p}$. Ioo) is possible

Likewise, experiment 3 made on 96 pigs, clearly showed that a gluten mixture (40 p. Ioo Gluten-feed +60 p. Ioo maize gluten) at 44 p. Ioo protein correctly re-balanced with lysine and used at a level of $25 \mathrm{p}$. I00, can provide $75 \mathrm{p}$. 100 of the complementary supply of protein.

The last digestibility experiment on $\mathrm{I} 6$ pigs allowed determination of the energy value of "Gluten-Feed \#, 2 goo kcal digestible energy/kg dry matter, corresponding to an apparent digestibility coefficient $(\mathrm{ADC})$ of the energy of $64 \mathrm{p}$. roo.

\title{
VALEUR NUTRITIVE DE L'URÉE \\ COMME SOURCE D'AZOTE INDIFFÉRENCIÉ \\ EN PRÉSENCE OU NON DE LACTOSE CHEZ LE PORC EN CROISSANCE-FINITION
}

\author{
A. RÉRAT et D. BOURDON \\ Laboratoire de Physiologie de la Nutrition, \\ Station de Recherches sur l'Élevage des Porcs, \\ Centre national de Recherches zootechniques, I. N.R. A., \\ 78350 Jouy en Josas
}

\section{RÉSUMÉ}

Deux expériences ont été réalisées en vue de préciser si la présence de glucides à digestion lente (lactose) introduits en quantité élevée, est susceptible de favoriser l'utilisation nutritive de l'urée chez le Porc en croissance-finition.

La première expérience a été réalisée sur 9 lots de 12 porcs ( 6 mâles castrés, 6 femelles). Les 8 régimes expérimentaux diffèrent du régime témoin semi-synthétique ( $\mathrm{I} 2 \mathrm{p}$. 1oo de farine de poisson), par substitution d'une fraction de protéines (3 p. Ioo) à l'aide d'urée ( $\mathrm{r}$ p. roo), et/ou d'un mélange rééquilibrant en acides aminés indispensables, et/ou par substitution d'une fraction (3o p. Ioo) des glucides de base (amidon ou maïs) par du lactose.

En alimentation semi ad libitum, l'addition d'urée se traduit par aucun effet bénéfique, ni sur la croissance, ni sur l'indice de consommation, pas plus que sur la composition corporelle, que ce soit en présence ou en l'absence d'un mélange rééquilibrant d'acides aminés indispensables et/ou de lactose. Par contre, l'addition de ces derniers, séparément ou ensemble, en présence ou en l'absence d'urée se révèle bénéfique.

La deuxième expérience réalisée en cage à métabolisme sur 16 castrats présente des modalités différentes : alimentation égalisée par paires, comparaison d'un régime témoin à I 2 p. Ioo de protéines de poisson avec 3 régimes expérimentaux dans lesquels 2 p. roo des protéines sont 